\title{
A Study Abroad Course Leads to Service Learning Project
}

\section{Dr. Charles McIntyre, Indiana University-Purdue University of Indianapolis}

Charles McIntyre is a Professor and Program Director of the Construction Engineering Management Technology Program at Indiana University Purdue University Indianapolis (IUPUI). He received a Ph.D. from Penn State in 1996. Prior to joining IUPUI, he was a faculty member and former chair in the Department of Construction Management and Engineering at North Dakota State University in Fargo. Dr. McIntyre's current research includes sustainable construction, green building, and industry-academic collaborations. $\mathrm{He}$ is an active member of the American Society for Engineering Education and the American Council for Construction Education. Dr. McIntyre has served on the ASEE Board of Directors and is an ASEE Fellow.

\section{Mr. Ryan A. Camp, Indiana University-Purdue University of Indianapolis Prof. Patricia Fox, Indiana University-Purdue University of Indianapolis}

Professor Patricia Fox is a Clinical Assistant Professor in the Department of Technology Leadership and Communication in the Purdue School of Engineering and Technology at Indiana University-Purdue University Indianapolis (IUPUI). Pat has been a member of the faculty for over 35 years. She has previously served as Associate Chair and Associate Dean in the School. Pat teaches leadership, ethics, sustainability, and study abroad courses. She has held a number of leadership roles in the American Society for Engineering Education (ASEE) including four terms on the ASEE Board as well as serving two times as the Chair of Engineering Technology Council. Pat is a Fellow of ASEE. Her research interests include sustainability and study abroad education.

\section{Shawn Patrick}

Shawn Patrick is the Faculty Development Program and Evaluation Director of the Indiana University (IU) School of Medicine Dean's Office of Faculty Affairs and Professional Development. Shawn is also an associate faculty in the Department of Technology Leadership \& Communication through the Purdue School of Engineering and Technology at IUPUI where he teaches courses in organizational leadership and technical communication. In his director role, Shawn supports faculty in their leadership, teaching, and research development. His research focuses on college teaching, faculty development, and the experience of minority faculty in STEM fields. Shawn teaches courses in ethics and leadership through OLS. Shawn holds a MA from Ball State University, and a BS from the University of Wisconsin-Oshkosh and is pursuing his $\mathrm{PhD}$ in Urban Education through IUPUI. 


\title{
A Study-Abroad Course Leads to a Service-Learning Project
}

\begin{abstract}
GO GREEN - Germany (ㅁreen Organizations: Global Responsibility for Environmental and Economic Necessity) is a study-abroad course offered at Indiana University-Purdue University Indianapolis. The course focused on sustainable practices in business and industry and involved classroom work and industry site visits prior to travelling to Germany for the 10-day studyabroad component. Upon return to the U.S., several students in the course participated in a service-learning project that focused on recycling, an aspect of sustainable practice. The studyabroad component provided the exposure to sustainability and fostered interpersonal relationships between the students, which contributed to the successful completion of the service-learning project. Some university funding was provided for this service-learning project. The project focused on establishing a recycling program at the St. Christopher Midsummer Festival, a 3-day event that attracts approximately 40,000 attendees. Prior to the implementation of this service-learning project, the festival did no recycling whatsoever. The contents of this paper document the background information, describe the methodology of the service-learning project, present the results, and provide recommendations and conclusions.
\end{abstract}

\section{Background}

Study-Abroad

In the GO GREEN - Germany study-abroad course, students participate in classroom activities during the end of the spring semester to learn about sustainable practices in businesses, industries, and municipalities as well as German culture. During this part of the course, site visits to local sustainable companies (Subaru of Indiana Automotive [14]), recycling firms (Ray's Trash Service [12] and RecycleForce [13]) and waste to energy facilities (Covanta Indianapolis [3]). The overseas component of this course is a 10-day experience in Germany (generally offered late May or early June) where the students visit organizations and facilities that parallel those they visited while in the U.S. (MVV Energies [8], Vauban, Freiburg [16] and the University of Kaiserslautern [15]). In addition, students are exposed to the culture of Germany as related to sustainability. All students write a technical paper that compares their learning experiences in the course concerning sustainable practices in the U.S. versus Germany. Students are encouraged to put into practice some of the lessons they have learned, which, for select students, led to the delivery of the service-learning project.

\section{Sustainability}

Sustainability is widely defined as stewarding the earth so that people living today meet their needs without jeopardizing the ability of future generations to meet their needs [17]. Current technologies allow the reuse and recycling of much of the standard waste streams. The Environmental Protection Agency (EPA) estimates that the energy savings from utilizing recycled material as opposed to claiming and processing raw materials is significant. Approximately, 10 million BTU per ton for office paper and 150 million BTU per ton for 
aluminum. Plastics are somewhere in the middle, ranging from 30 to 50 million BTU saved per ton $[5]$.

The Indiana Recycling Coalition (IRC) [7] examined Indiana's municipal solid waste to determine what waste materials are landfilled or incinerated (energy from waste). The IRC reported that less than $10 \%$ of the waste streams were actual nonrecyclable trash. Of the 8.6 million tons of refuse collected in 2012 which included waste from surround states that is shipped to Indiana landfills (approximately $30 \%$ of the total tonnage), $66 \%$ were recyclable, $17 \%$ were compostable, and another $9 \%$ other recoverable materials (electronics and precious metals) with only $8 \%$ identified as true refuse. The IRC study stated that with an increase of $50 \%$ in the recycling rate that potentially 20,000 new jobs would be created in the sorting and rerouting recyclables and composting. Reclaiming recyclable materials would serve as inputs into Indiana industrial processes.

The Environmental Protection Agency (EPA) [4] estimates that Americans generate approximately four and a half pounds of waste per person per day for a national total of twohundred and fifty-eight million tons. Of that total, 34\% percent was recycled, $12 \%$ percent was burned with energy capture, and the remaining 54\% percent was sent to landfills.

St. Christopher Church where the Midsummer festival is held is a catholic church. Therefore, it seems appropriate to highlight a section of a recent encyclical from Pope Francis, the leader of the catholic faith. In 2014, Pope Francis delivered an encyclical on the environment and human ecology. "Laudato de si" [10] which calls upon all peoples of the world, especially those of the Christian faith, to recognize the Earth as sacred and to direct daily actions accordingly. By focusing attention on what can be done at the individual and local levels, individuals and communities become accountable for preserving resources and living in a more sustainable manner. Joining in this call are a number of other faith leaders.

Germany has been addressing sustainable policy and practices in business, industry and within their municipalities for decades. The results are impressive when considering sustainable urban structures and planning, renewable energy usage, national recycling, sustainable transportation systems, and green policies at the local, state, and federal levels that has helped fuel economic growth and stability [11]. Germans are recycling at nearly twice the rate of Americans making Germany the world's leading recycling country with $62 \%$ of total waste recycled [9].

\section{Service-Learning}

Service-learning can be defined as "a form of experiential education in which students engage in activities that address human and community needs together with structured opportunities for reflection designed to achieve desired learning outcomes" [2].

Upon return to the U.S. from the study abroad experience in Germany, the faculty advisors, one graduate student and two undergraduate students in the course were involved in the servicelearning project. The goal of this project was to initiate a recycling program at the St.

Christopher Midsummer Festival, which previously, had no recycling program. The planning stages for this project began in February 2017. A proposal was submitted to the IUPUI Service- 
Learning Office for $\$ 1,800$ and approved for funding to cover miscellaneous expenses and provide a stipend for the graduate students. The overriding intent of this project was to take to heart the philosophy, principles, and practices of sustainability and apply it to a community project.

\section{St. Christopher Midsummer Festival}

St. Christopher is a catholic parish located in Speedway on the west side of Indianapolis. The 80th annual St. Christopher Midsummer Festival took place July 13-15, 2017 on the campus of St. Christopher Church. The festival offered food and drink, carnival rides, gaming, and live music. Hours of operation were from 4:00 to 10:00 PM on Thursday and Friday (July 13 \& 14) and from 12:00 to 11:00 PM on Saturday (July 15). Approximately 40,000 people attend the three-day event where a significant amount of waste was generated. Prior to 2017, waste was not sorted or recycled. All waste was collected by Ray's Trash Service and hauled to Covanta Indianapolis, a waste to energy facility. Figure 1 illustrates the site layout of the festival.

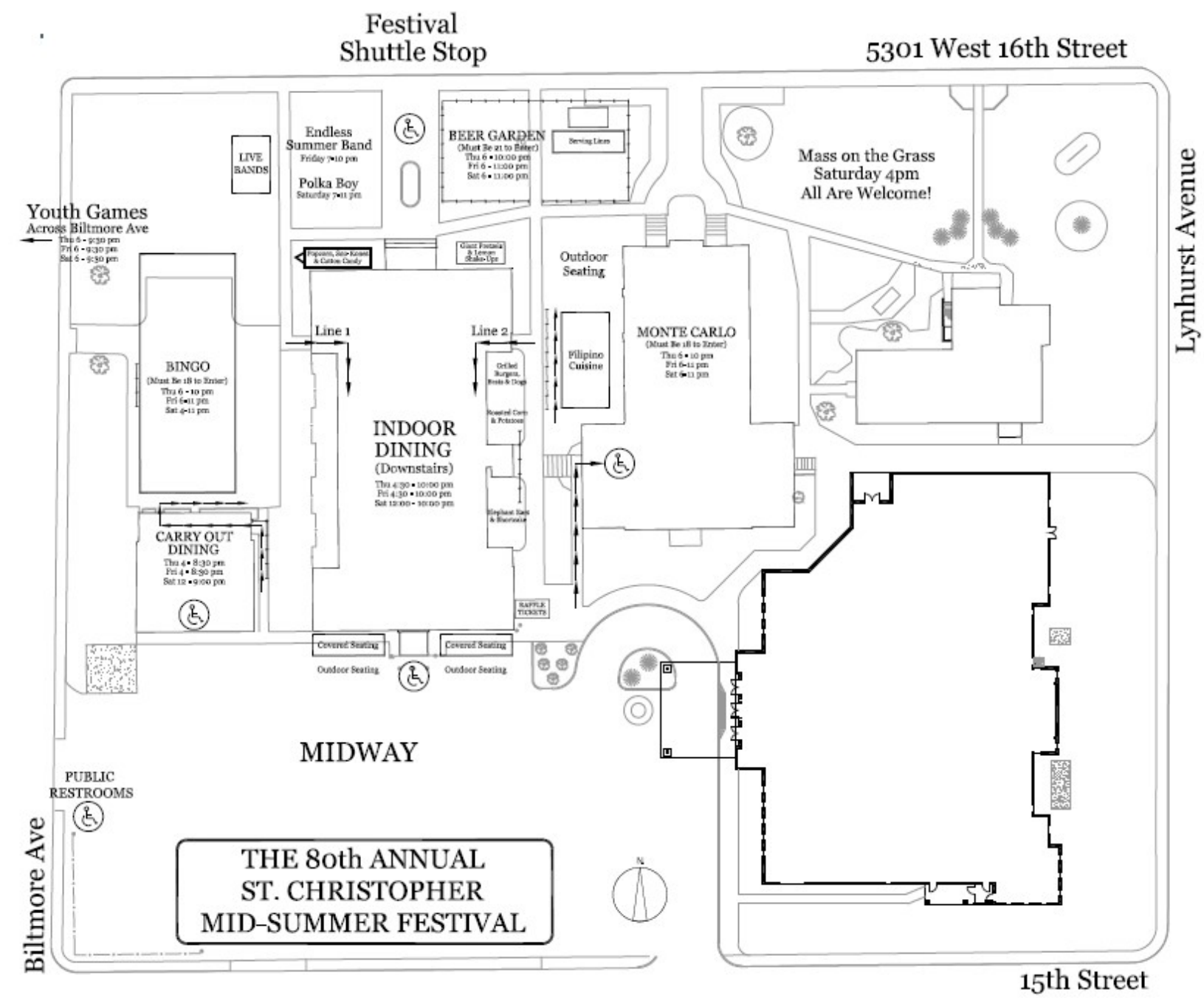

Figure 1 - Festival Site Layout 
The festival facilities that generated waste were characterized in two ways. The first were those that were sponsored by the festival and second those that were external vendors. Table 1, on the following page, provides an overview of the facilities and their locations.

Table 1 - Festival Facilities

\begin{tabular}{|l|l|}
\hline \multicolumn{1}{|c|}{ Facility } & \multicolumn{1}{c|}{ Location } \\
\hline Indoor Dining & School Basement \\
\hline Carry Out Dining & Bus Garage \\
\hline Bingo & Tent - North of the Bus Garage \\
\hline Beer Garden & North Lawn \\
\hline Monte Carlo Casino Snack Stand & School Gymnasium \\
\hline Food Court & Between School and Casino \\
\hline External Food Vendors & Throughout the Midway \\
\hline
\end{tabular}

\section{Waste Streams and Recyclable Materials}

Table 2 identifies the waste streams from the various festival facilities.

Table 2 - Waste Streams

\begin{tabular}{|l|c|}
\hline \multicolumn{1}{|c|}{ Facility } & Waste Stream (refer to the Key) \\
\hline Indoor Dining & $1,4,5,6,7,10,11,12$ \\
\hline Carry Out Dining & 11,12 \\
\hline Bingo & 2 \\
\hline Beer Garden & 6 \\
\hline Monte Carlo Casino Snack Stand & $1,3,4,5,6,7,8,9,10$ \\
\hline Food Court & $1,4,5,6,7,10,11$ \\
\hline External Food Vendors & $1,3,7,10$ \\
\hline
\end{tabular}

\begin{tabular}{|c|l|}
\hline \multicolumn{2}{|c|}{ Key } \\
\hline 1 & Paper Plates and Napkins \\
\hline 2 & Paper (pull tabs and bingo sheets) \\
\hline 3 & Paper (containers and wrappers) \\
\hline 4 & Misc. Paper (sugar packets, etc.) \\
\hline 5 & Plastic Utensils \\
\hline 6 & Plastic Cups \\
\hline 7 & Plastic Bottles \\
\hline 8 & Aluminum Cans \\
\hline 9 & Glass Bottles \\
\hline 10 & Food Waste \\
\hline 11 & Styrofoam \\
\hline 12 & Cardboard \\
\hline
\end{tabular}


Not all of the above waste can be recycled due to criteria set by Ray's Trash Service. Table 3 indicates which materials are acceptable or unacceptable for recycling.

Table 3 - Acceptable and Unacceptable Materials for Recycling

\begin{tabular}{|c|l|c|}
\hline 1 & Paper Plates and Napkins & Unacceptable \\
\hline 2 & Paper (pull tabs and bingo sheets) & Acceptable \\
\hline 3 & Paper (containers and wrappers) & Unacceptable \\
\hline 4 & Misc. Paper (sugar packets, etc.) & Acceptable \\
\hline 5 & Plastic Utensils & Unacceptable \\
\hline 6 & Plastic Cups & Acceptable \\
\hline 7 & Plastic Bottles & Acceptable \\
\hline 8 & Aluminum Cans & Acceptable \\
\hline 9 & Glass Bottles & Acceptable \\
\hline 10 & Food Waste & Unacceptable \\
\hline 11 & Styrofoam & Unacceptable \\
\hline 12 & Cardboard & Acceptable \\
\hline
\end{tabular}

\section{Methodology}

The primary goal of the service-learning project was to initiate a recycling program for the festival. In February 2017, faculty advisors met with the festival organization committee to discuss the recycling project. Permission was granted for this recycling program provided that no festival workers were involved and that all work related to the recycling program was to be done by persons involved in the service-learning project.

In May 2017, faculty advisors contacted d Trash Services to determine the means for accomplishing the recycling program. Ray's agreed to provide cardboard containers for the project at no cost. The containers were stacked flat and needed assembly. No covers were available for the containers. When assembled, the containers measured 0.61 meters ( 2 feet $)$ square by 0.91 meters ( 3 feet) in height. Ray's would also provide a large metal collection bin and agreed to place and empty the bin at no cost. The dimensions of the recycling bin were 1.8 meters ( 6 feet) square by 2.1 meters ( 7 feet) high. Ray's would also empty the bin periodically throughout the festival at no cost.

In July 2017 prior to the festival, faculty advisors and students acquired 24 cardboard containers from Ray's Trash Service. Twenty containers were assembled. The remaining four containers were used to fabricate removable covers. Circular holes were cut into covers and measured 10.2 centimeters (4 inches). Plastic coated signage was attached to the covers indicated what materials could be recycled, namely, paper; plastic cups and bottles; aluminum cans, and glass bottles. Plastic bags (170 liter, 45 gallon) were placed inside the cardboard containers. Cardboard waste from the indoor and carry out dining would be recycled directly into the large recycling bin and would be handled by the festival staff. Virtually all cardboard was from food packaging (frozen fish, perishables, etc.) and was clean of food waste. 


\section{Festival Work}

On Thursday, July 13 prior to the start of the festival, twenty collection containers were placed on the festival grounds. These locations were initially determined by the generation of the waste streams and the location of designated seating areas. Figure 2 indicates the locations of the collection containers as indicated by the circles. The shaded square shows the location of the large recycling bin. In addition, other non-recyclable containers (trash cans) were on site and serviced by festival workers. Where appropriate, the recycling containers were placed adjacent to the trash cans.

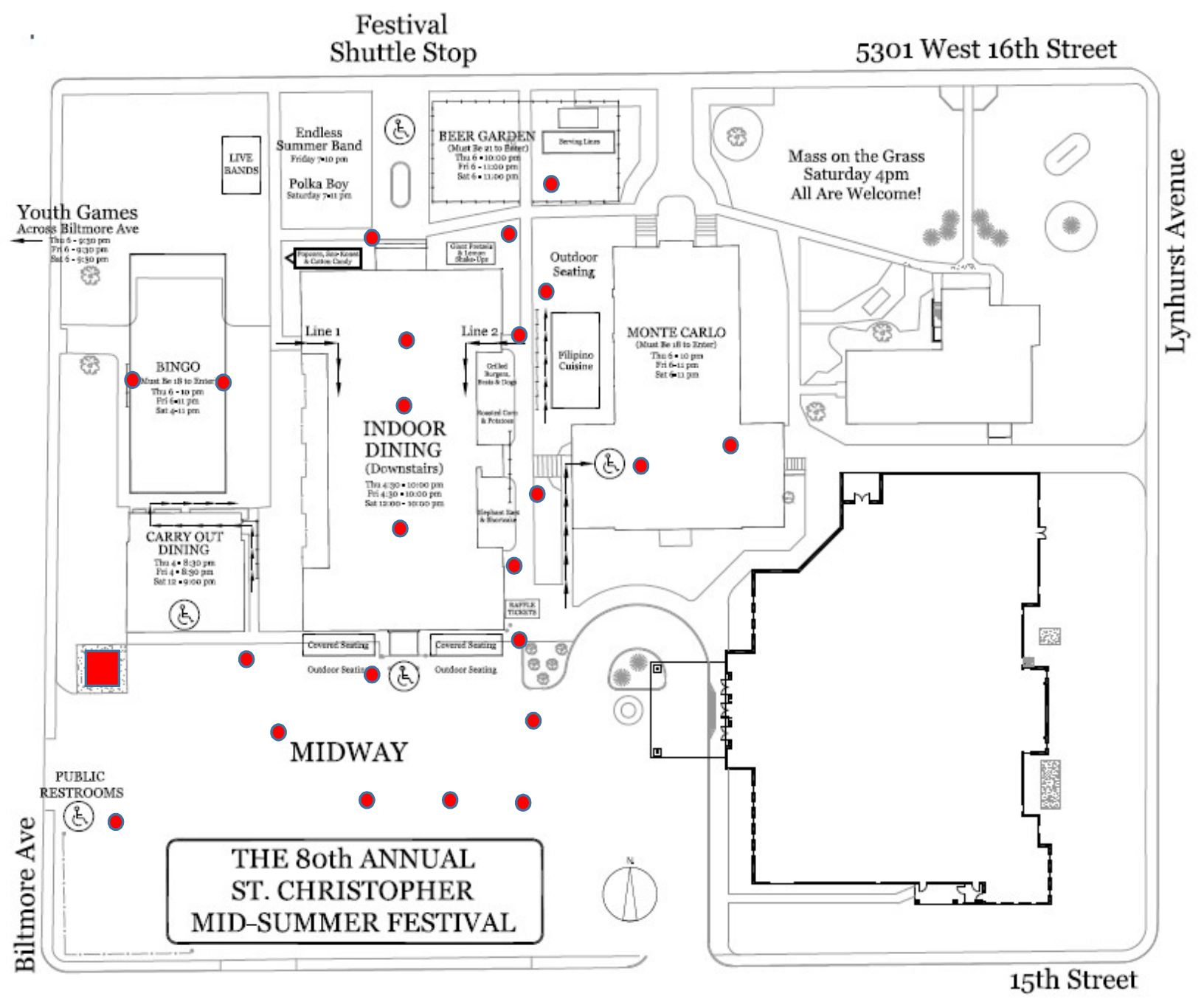

Figure 2 - Location of the Recycling Containers and Bin

The following bullet items outline the work that was conducted during and after the festival by the faculty and students.

- Monitor the volume of the recycling containers and encourage their use.

- Replace the bag liners and empty waste into recycling bin.

- Observe and estimate the quantities and characteristics of each waste stream. 
- Based on volumes generated, reposition the containers to higher areas of recycled collection.

- Final clean up and recycle all cardboard containers (post-festival).

\section{Results}

Upon collection and disposal of the collected recycling containers, observations and estimates were performed to determine the waste volumes and the characteristics of the waste that was deposited into the recycling bins. Table 3 presents the daily totals in both number of containers and estimated volumes of the recycled materials.

Table 3 - Daily Recycling Totals

\begin{tabular}{|l|c|c|}
\hline \multicolumn{1}{|c|}{ Day } & No. of Containers Emptied & Estimated Volume \\
\hline Thursday, June $13(6-10 \mathrm{PM})^{1}$ & 10 & 2.12 c.m. (75 c.f.) \\
\hline Friday, June 14 $(4-10 \mathrm{PM})$ & 25 & 4.24 c.m. $(150$ c.f.) \\
\hline Saturday, June $15(12-11 \mathrm{PM})$ & 45 & 8.50 c.m. $(300$ c.f.) \\
\hline TOTALS & 70 & 14.86 c.m. (525 c.f.) \\
\hline
\end{tabular}

1 Inclement weather (thunderstorms) reduced anticipated attendance.

2 Not all bag liners in the containers were at capacity.

3 Disposal bin was full and emptied by Ray's Trash Service on Saturday morning.

4 Disposal bin overflow, extra bags placed adjacent to bin for collection.

In addition to volumes, the characteristics of the waste was also estimated. Based on location the characteristics of the waste varied. For example, waste from Bingo was mostly paper (pull-tabs and bingo sheets), while the waste from Monte Carlo was mostly containers (plastic cups and bottles, aluminum bottles, and glass bottles).

Not all the waste deposited into the recycling containers was recyclable. Non-recyclable amounts would vary based on location and time of day. For example, it was observed that at dining times (5-7 PM and 12-2 PM Saturday) more non-recyclable wastes (paper plates, napkins, and food waste) was placed in the recycling containers than at other times during the festival. It was also observed that at the final pick-up (late Saturday evening at the conclusion of the festival) a higher percentage on non-recyclable waste was observed. In addition, all cardboard waste was handled independently by the festival staff and was not included in this estimate. It was still possible to determine the general characteristics of the waste streams as approximate percentages (by volume), as listed in Table 4.

Table 4 - Total Recyclable Waste Stream Characteristics

\begin{tabular}{|l|c|}
\hline \multicolumn{1}{|c|}{ Waste Stream } & Percent \\
\hline Plastic Cups & 30 \\
\hline Plastic Bottles & 30 \\
\hline Aluminum Cans & 15 \\
\hline Paper (pull tabs and bingo sheets) & 10 \\
\hline
\end{tabular}




\begin{tabular}{|l|c|}
\hline Glass Bottles & 5 \\
\hline Non-Recyclable Waste $^{1}$ & $10^{2}$ \\
\hline \multicolumn{1}{|c|}{ TOTAL } & 100 \\
\hline
\end{tabular}

1 Paper plates and napkins, paper (containers and wrappers), plastic utensils, food waste, and Styrofoam.

2 The $10 \%$ estimate seems reasonable, since $10 \%$ of all residential waste processed by Ray's Trash Service is non-recyclable.

Information in Table 4 indicates that $80 \%$ of the reclaimed recyclable materials consisted of beverage containers (plastic cups, plastic bottles, aluminum cans, and glass bottles). Based on pure observation of the recycling waste stream to the trash waste steam, it was estimated that $50 \%$ to $70 \%$ of the beverage containers were recycled. This is an estimate at best, but even if it were at or below $50 \%$, this is a vast improvement from last year when the recycling rate was $0 \%$.

\section{Post Project Follow Up}

A post-project interview was conducted with the principal of the St. Christopher Elementary School. The purpose of this interview was to determine school procedures with respect to sustainable practices and recycling. The intent of this interview was to determine if some of those procedures could be integrated into the festival practices.

The principal indicated that the school community is taking the statements of Pope Francis to heart. They recycle paper via an Abitibi [1] paper retriever dumpster on campus. Every Thursday sixth graders at the school collect waste paper, shred it, and ferry it to the dumpster. In the cafeteria, where approximately 200 children are served lunch during school days, they utilize trays, plates, cups, and utensils that are cleansed and sanitized in their dishwashers. Excess food is donated to soup kitchens. The school also supports the needy in the community by operating a food pantry on the school site on Tuesdays and Fridays. Creation care is taught within the religion and science curricula, which essentially means the mobilization of the church community care for God's creation. Applying some of these sustainable practices to the festival using the facilities of the school are not realistic from a logistical standpoint and due to the sheer number of festival attendees. However, other opportunities do exist using school resources and personnel that will assist in increasing sustainable practices at the festival. These will be discussed in the following section of this paper.

\section{Recommendations and Conclusions}

By any reasonable measure, one would conclude that the festival recycling project was a success, arguable only to the degree of success. This effort will continue for the 2018 festival and planning for an expanded effort has already begun. The following recommendations, i.e., "lessons learned" from the 2017 festival will discussed with the festival planning committee in February 2018 to determine which are feasible and to what extent. The primary areas discussed are categorized as programs, visibility, and education. 


\section{Programs}

The basic program to collect recyclable materials will continue. A potential expansion could be composting food wastes. The plan is to start within the more controlled environments, namely the indoor dining and gaming areas. No trash cans would be placed in these areas, only the recyclable containers. Serving trays and plates would be returned to the "sorting area," where all waste would be sorted, recyclable and nonrecyclable. Sorting would be done by volunteers, perhaps $5^{\text {th }}$ or $6^{\text {th }}$ grade students of the school. Food waste is the primary concern. Containers would be available for just the food waste. Preliminary contact has been made with Green with Indy [6], a commercial and residential compost and food waste hauling service. It is anticipated that they can assist in the planning and delivery effort of the composting effort.

Some research and discussion has been conducted concerning the use of recyclable plates and utensils. This is a more expensive option; however, all options must be weighed. Further discussion will determine if this is a feasible option for 2018. Packaging of food and beverages delivered to the festival could also be a topic for discussion.

\section{Visibility}

Based on input from festival attendees and from observation of the service-learning workers, it was clear that an increase in signage was needed to inform people of this "new" option. It was also determined that visuals are more effective than text. Pictures depicting the recyclable materials would likely aid in the recycling effort.

Based on attendee comments, another concern was the recycling containers. People were not used to seeing or using cardboard boxes for recycling. It may be possible to obtain containers with a more recognizable "recycle" look, but these are items that come with a cost and are not typically donated. Discussions will continue with Ray’s Trash Service.

\section{Education}

In a very general sense, continued education for the community at large concerning the importance of recycling is warranted. Within the city limits of Indianapolis, recycling is not required. The city does have recycling in many neighborhoods, but there is a cost. Others chose to do self-recycling, where they bring their recyclables to local collection bins, typically located in at a supermarket parking lot. These is no direct cost to the user of this service. The majority of residents in Indianapolis chose to just not recycle, either for convenience, cost considerations, lack of transportation, or apathy. Education is a key component when (as was the case at the festival) recycling is readily available and takes no more effort than disposing of trash and still many festival goers chose not to recycle.

At the parish level much more could be done. Advanced advertising in the weekly parish bulletin, which is available at all masses and on line, would be a relatively easy and no cost solution to "get the word out." Some responsibility falls upon church and parish leaders to follow the lead of the school and speak about the importance of creation care to their faith. These leaders do have significant influence on parishioners. 
It is entirely possible that the St, Christopher Midsummer Festival could be a zero-waste event, a noble achievement and one not easily reached. However, even modest improvements in the recycling campaign could serve as a model for other parishes and organizations and could result in a greater individual recycling rate at home.

On a global or even community scale, one may argue the overall significance of recycling, but one cannot argue that recycling does reduce waste volumes that would otherwise be landfilled or incinerated. Recycling does preserve natural resources. In an economic sense, recycling does produce jobs, typically for those in most need.

In conclusion, the lessons learned from the study-abroad experience were applied to an actual service-learning project that did have an impact that left a very positive impression with the project participants. Something was accomplished. In the true spirit of sustainability, this project will continue and will be expanded.

\section{References}

[1] Abitibi Consolidated, http://www.abitibiconsolidated.com/ACIWebSiteV3.nsf/Site/en/index.html

[2] B. Jacoby, Service-Learning in Higher Education: Concepts and Practices. Jossey-Bass, 1996.

[3] Covanta Indianapolis, https://www.covanta.com/Our-Facilities/Covanta-Indianapolis

[4] Environmental Protection Agency, Advancing Sustainable Materials Management. 2016. https:/www.epa.gov/sites/production/files/201611/documents/2014_smmfactsheet 508.pdf

[5] Environmental Protection Agency. Warm Version 13. 2015. https://www3.epa.gov/warm/pdfs/Energy_Impacts.pdf

[6] Green with Indy, https://www.greenwithindy.com/

[7] Indiana Recycling Coalition, The Untapped Job Potential of Indiana's Recycling Industry. 2013. http://indianarecycling.org/wp-content/uploads/2013/12/IRC-2013-Recycling-JobStudyNEW.pdf

[8] MVV Energie, https://www.mvv.de/en/

[9] Planet Aid 2015 Annual Report. http://www.planetaid.org/annual-report-2015

[10] Pope Francis, Laudato Si Enciclical. 2015. https://laudatosi.com 
[11] R. Buehler, R., A. Jungjohann, M. Keeley, and M. Mehing, How Germany Became Europe's Green Leader: A Look at Four Decades of Sustainable Policymaking. Solutions. Vol 2, Issue 5, 2011.

[12] Rays Trash Service, https://raystrash.com/our-services/recycling/

[13] RecycleForce, http://recycleforce.org/

[14] Subaru Of Indiana Automotive, http://subaru-sia.wixsite.com/indiana/info

[15] University of Kaiserslautern, http://www.uni-kl.de/en/university/

[16] Vauban, Freiburg, http://www.madisonfreiburg.org/green/vauban.htm

[17] World Commission on Environment and Development (Brundtland Report), Our Common Future. Oxford University Press, p. 27, 1987. 